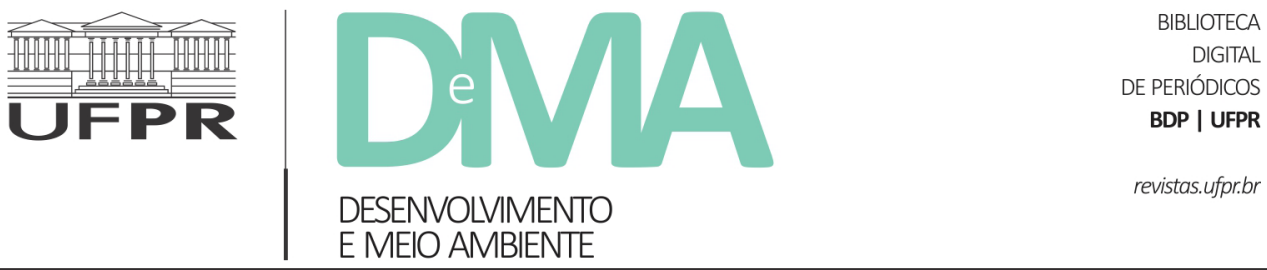

\title{
O princípio responsabilidade em Hans Jonas como proposta de ética para uma sociedade sustentável
}

\section{Responsibility principle in Hans Jonas as a proposal of ethics for a sustainable society}

\author{
Alesi LEAL ${ }^{1,2^{*}}$, Daniel DURANTE ${ }^{1}$ \\ ${ }^{1}$ Programa Regional de Pós-Graduação em Desenvolvimento e Meio Ambiente (PRODEMA), Universidade Federal do Rio Grande do Norte \\ (UFRN), Natal, RN, Brasil \\ ${ }^{2}$ Programa Regional de Pós-Graduação em Desenvolvimento e Meio Ambiente (PRODEMA), Universidade Federal de Sergipe (UFS), São \\ Cristóvão, SE, Brasil \\ ${ }^{*}$ E-mail de contato: alesi_leal@hotmail.com
}

Artigo recebido em 10 de fevereiro de 2020, versão final aceita em 12 de novembro de 2020, publicado em 27 de julho de 2021.

RESUMO: O objetivo do texto é apresentar o princípio responsabilidade em Hans Jonas como proposta de ética para uma sociedade sustentável. Em meio aos efeitos destrutivos à natureza e problemas ambientais resultantes da atividade técnico-científica, o princípio responsabilidade é proposto como um novo conteúdo de ética que faz repensar o agir humano para com a natureza, de modo a ampliar as considerações morais para além do cunho antropocêntrico e do círculo imediato da ação do aqui e do agora, fazendo refletir sobre o cuidado com as demais formas de vida não humanas, os efeitos e consequências globais da ação humana e as próximas gerações. Nesse caminho, torna-se imprescindível a ampliação do horizonte temporal para que a preocupação com o futuro seja patente. Essas características revelam a importância da ética da responsabilidade no contexto da ética ambiental, renovando a teoria da filosofia moral e fornecendo subsídio à noção de sustentabilidade enquanto valor para a sociedade atual. Assim, o artigo representa uma contribuição para o debate contemporâneo sobre ética ambiental nas ciências ambientais, sob uma perspectiva interdisciplinar.

Palavras-chave: ética; responsabilidade; Hans Jonas; meio ambiente; sustentabilidade.

ABSTRACT: The objective of the text is to present the responsibility principle in Hans Jonas as a proposal for ethics for a sustainable society. Amid the destructive effects on nature and environmental problems resulting from technical-scientific activity, the principle of responsibility is proposed as a new content of ethics that makes rethinking human action towards nature, in order to broaden moral considerations beyond the stamp anthropocentric and the immediate circle of action here and now, making us reflect on the care for other nonhuman forms of life, the global effects and consequences of human action and the next generations. In this 
way, it is essential to expand the time horizon so that the concern with the future is clear. These characteristics reveal the importance of the ethics of responsibility in the context of environmental ethics, renewing the theory of moral philosophy and providing support for the notion of sustainability as a value for today's society. Thus, the article represents a contribution to the current debate on environmental ethics in environmental sciences, from an interdisciplinary perspective.

Keywords: ethic; responsibility; Hans Jonas; environment; sustainability.

\section{Introdução}

O presente artigo parte do pressuposto de que a instauração da crise ambiental que atinge a humanidade é resultado do soerguimento da sociedade moderna, que se desenvolveu historicamente com base na política do crescimento econômico capitalista. O desenvolvimento desse sistema social, que vê o ambiente natural como um depósito de matérias-primas para produção de mercadorias e acúmulo de capital e a natureza como um sistema aberto para toda e qualquer manipulação tecnocientífica, deixou a natureza em estado depreciativo, a tal ponto que se fala em crise ambiental devido aos níveis de degradação e ameaças ao meio ambiente deixados pelo ser humano por meio da atividade técnica e industrial.

As consequências foram e ainda têm sido desastrosas, nunca vistas anteriormente, causando o esgotamento progressivo dos recursos naturais e o consequente colapso ecológico, o aumento da poluição nos diversos meios naturais (solo, água e ar), assim como o aumento progressivo da população, a eminente ameaça de uma guerra atômica, a possibilidade de manipulação genética. Esses são os principais perigos e ameaças que revelam o caos deixado como herança da civilização tecnológica. $\mathrm{O}$ poder opressivo que a humanidade passou a exercer sobre a natureza, invadindo seus domínios sem precedentes, colocou não somente esta em risco, mas a própria humanidade. Ou seja, o dilema que assola o futuro da humanidade atinge a integridade da natureza, mas também a do próprio ser humano, perfazendo a ameaça de autodestruição de toda a vida no planeta e denunciando, assim, o estado crítico do meio ambiente.

Com isso, a humanidade é posta diante de um dos problemas de ética mais sérios do século XXI. A crise ambiental, ou, em outras palavras, o risco à conservação da vida no planeta, deflagra-se como um problema ético à medida que denuncia as motivações do agir humano baseadas na assertiva moderna de progresso ${ }^{1}$, isto é, está ligado a uma lógica de ação, enquanto fruto da exploração da natureza por meio da técnica, os quais nos fizeram chegar aos níveis de degradação atuais.

Considerando a ética como a reflexão racional sobre os fundamentos da boa vida (Baudrillard, 1990), emerge a pergunta: por que ainda há impasse no que diz respeito ao agir humano responsável e cuidadoso (Jonas, 2006) para com o meio ambiente? $\mathrm{Ou}$, mais diretamente, como disse Karl-Otto Apel (1994, p. 172), no que se refere a "[...] uma ética de responsabilidade solidária em face da crise ecológi-

\footnotetext{
${ }^{1}$ A assertiva moderna de progresso deve ser entendida, neste contexto, como aquela pregada pela máxima baconiana "saber é poder".
} 
ca da civilização técnico-científica"? Em face das consequências destrutivas de nossa ação técnica, parece ser necessária uma postura que reoriente ética e politicamente uma sociedade marcada pelo acirramento da crise ambiental e que considere a sustentabilidade do planeta e a responsabilidade para com as próximas gerações.

Nesse contexto, Hans Jonas tentou resolver essa questão quando propôs uma ética da responsabilidade, a qual redirecionaria o agir humano com vistas à sobrevivência planetária. Para ele, devido à intervenção dominadora do ser humano sobre a natureza, atitudes urgentes seriam necessárias. As próximas gerações devem ser levadas em conta, assim como a qualidade do meio ambiente. Por isso, por meio de sua principal obra, O Princípio Responsabilidade: ensaio de uma ética para a civilização tecnológica (Das Prinzip Verantwortung: Versuch einer Ethic für die Technologische Zivilisation, do original, em alemão), ele busca constituir uma proposta importante e necessária diante do cenário da crise ambiental.

Nela, o autor afirma que o poder destrutivo que a tecnologia alcançou na sociedade estaria requerendo de nós a estruturação de uma nova ética, a formulação de um novo princípio ou, dito de outra forma, um novo imperativo para a moral que fosse capaz de pôr freios voluntários à evolução tecnológica acelerada e descontrolada, a fim de que não só a natureza seja conservada, mas a existência humana também. Assim, ele parte do papel central que a técnica assume na civilização moderna e expressa porque ela se tornou um objeto da filosofia e, por conseguinte, também um objeto da ética.

Portanto o objetivo do texto é apresentar o princípio responsabilidade em Hans Jonas como proposta de ética para uma sociedade sustentável. Buscou-se analisar a teoria e a prática do princípio jonasiano, sua relevância no contexto do campo da ética ambiental e de que forma ele se relaciona com e fornece subsídio à noção de sustentabilidade enquanto valor social. Para isso, o texto aborda o seguinte percurso teórico-metodológico: a) o contexto do princípio responsabilidade na ética ambiental; b) a responsabilidade como proposta de ética; c) a relação entre o princípio responsabilidade e a sustentabilidade. Esses três aspectos visam destacar, em linhas gerais, as principais características da responsabilidade enquanto novo conteúdo de ética emergente no que tange ao princípio da ação humana, a forma como lida com o risco, sua relação com o prognóstico, a previsibilidade e a prática desses novos conceitos de "bem" e de "mal" que a heurística do temor preconizam e podem, assim, impelir a sociedade a adotar comportamentos mais sustentáveis e ajudá-la a lidar com a crise ambiental.

\section{Contextualização na ética ambiental}

O princípio responsabilidade, proposto por Jonas, emerge da necessidade urgente de se reconsiderar as dimensões da moralidade do agir humano diante das consequências desastrosas da degradação ambiental.

Até então, a ética tinha um caráter eminentemente antropocêntrico, no sentido de que dizia respeito somente ao relacionamento dos seres humanos uns com os outros ou de cada ser humano consigo mesmo. Ou seja, ela ocorria "no interior do enclave humano, sem tocar a natureza das coisas" (Jonas, 2006, p. 33).

Nos anos 1960, pós-Segunda Guerra Mundial, percebeu-se como o ser humano tinha adquirido capacidades transformadoras e ocasionado efeitos 
gerais destrutivos que passaram a ser temidos, como extensão e multiplicação das poluições, esgotamento dos recursos, desaparecimentos ou destruições irreversíveis, dentre outros (Larrère, 2010², p. 406).

A partir da evolução do debate sobre questões envolvendo o meio ambiente, como a proteção de florestas tropicais, criação e preservação de parques nacionais e até mesmo abordagem global abrangente sobre a produção de gases do efeito estufa, é que se passou a discutir sobre a relevância da natureza enquanto domínio representativo da moralidade. Assim, a maioria dos filósofos no início dos anos 1970 teve como principal questão a reflexão sobre o valor moral da natureza em si mesma, diga-se, seu valor intrínseco, ao invés de atribuir-lhe valor indireto, quando leva-se em conta apreciação ou necessidade humana (Light, 2005).

É bem verdade que ser humano e natureza relacionam-se entre si e esta permite o desfrute de diversos benefícios, como o gozo estético, oportunidades de ócio e investigação, significação espiritual e fornecimento de diversos recursos e serviços ambientais (Elliot, 2004, p. 391). Porém é intransponível a percepção de que há bons e maus modos de se conduzir na natureza, que nos liga aqui a outros limites (futuros) que as de nossa potência técnica. Que nós temos deveres, que ela tem, talvez, direitos. Que a natureza, então, tem um valor moral (Routley, 1973).

Essa ideia, não completamente nova, que coloca em foco a atenção à natureza, ressoou durante o século XIX e passou a ser indissociável das rápidas transformações ambientais, consequências da industrialização. São as sociedades industriais, e as únicas, que formularam e deram sentido a um projeto de proteção da natureza destinado a dar espaço ao limite do desenvolvimento econômico e industrial (Larrère, 2010, p. 405).

Por exemplo, considerando a construção hipotética de um grande shopping em uma localidade próxima do encontro de determinado rio com o mar, em uma cidade brasileira, em área de manguezais ${ }^{3}$, os empresários justificariam o empreendimento como importante quando se considera a geração de empregos e renda, o aumento do fluxo comercial e o crescimento da economia local. Todavia os opositores à construção do shopping, considerando a relevância ecossistêmica e ecológica dos manguezais, afirmariam que este certamente ocasionaria diversos impactos ambientais negativos, incluídos a perda geral de biodiversidade, a retirada da vegetação característica, morte e riscos à reprodução de determinadas espécies de animais.

Essa situação hipotética nos auxilia a pensar sobre os diferentes tipos de argumentos que podem surgir entre grupos opostos que só fazem sentido ante a certo tipo de contexto. As diferenças de cada contexto dão lugar a valorações distintas do que se deve fazer, revelando-se, assim, o dilema ético a ser resolvido. Tal contexto se constitui de coisas tais, como desejos, preferências, aspirações, metas e princípios, incluso princípios morais (Elliot, 2004, p. 392).

\footnotetext{
${ }^{2}$ Texto original publicado em: Natures Sciences Sociétés 2010/4 (Vol. 18), p. 405-413. Tradução para o português por Antônio Carlos dos Santos, com a devida autorização da autora.

${ }^{3}$ Este é um tipo de empreendimento com tais especificidades do contexto em que é empreendido que chega a ser comum em algumas cidades e capitais do Nordeste brasileiro, como em João Pessoa-PB, Recife-PE e Aracaju-SE, por exemplo.
} 
Com efeito, uma reflexão sobre o que está envolvido na resolução da controvérsia sobre a construção do shopping faz emergir os elementos relevantes para qualquer tentativa de responder questões como: É moralmente aceitável causar a extinção de uma espécie? Se é, em que circunstâncias, se não, por que não? Quais circunstâncias tornam moralmente aceitável que nós humanos provoquemos a morte de animais? Quais os limites da moralidade das nossas práticas de abater animais? Haveria imoralidade nas nossas ações que têm produzido degradação generalizada sobre um ecossistema? Se sim, como e quais os critérios e parâmetros para o julgamento dessas ações como imorais? E quem seriam os atores imorais responsáveis por essas ações? Seria melhor proteger os manguezais em questão ou criar uma riqueza material maior que melhore a vida de determinadas pessoas? A extinção de uma espécie ou morte de animais constitui um preço aceitável a ser pago pelo aumento das oportunidades de emprego?

Sob essa expansão do regime de compreensão, surge a ética ambiental como um ramo da ética aplicada que se preocupa com os fundamentos morais para a preservação e restauração do meio ambiente (Light, 2005, p. 635) e reflete sobre o lugar do ser humano na natureza, no mundo. Ela foi elaborada em torno da ideia de valor intrínseco, e das entidades naturais, ou da natureza como um todo.

A expressão "valor intrínseco" pode ser encontrada em Kant, que afirma que tem um valor intrínseco tudo o que deve ser tratado como um "fim em si mesmo"; ou seja, a humanidade e, mais especificamente, todo ser racional. Todo o resto só é considerado como meio, como um valor instrumental. O filósofo teoriza: "Os seres cuja existência dependem, para dizer a verdade, não da nossa von- tade, mas da natureza, têm, no entanto, quando são seres privados da razão, apenas um valor relativo, o dos meios, e isso é por que eles são chamados de coisas" (Kant, 1984, p. 294).

A natureza adquiriu esse valor instrumental e, portanto, passou a ser considerada de valor moral indireto porque é a fonte de coisas para as necessidades humanas, como recursos naturais, usados para fornecer as bases para a construção e sustentação das comunidades humanas (Light, 2005, p. 635). Todavia a ética ambiental vai nomear "antropocêntrico" essa posição que só reconhece dignidade moral aos homens e deixa fora de seu campo todo o resto, ou seja, a natureza, vista como um conjunto de recursos. A tônica da ética ambiental é, ao contrário, mostrar que as entidades naturais têm uma dignidade moral, que elas têm valor intrínseco (Larrère, 2010, p. 407).

A compreensão advém de uma flutuação do regime de percepção, que perfaz a ideia de que aí, onde há meios, há necessariamente fins. Ora, todos os organismos vivos, sejam eles simples ou complexos, quer se trate de animais (provido ou não de sensibilidade), de vegetais ou de organismos unicelulares, todos implicam para se conservar na existência, e poderem se reproduzir. Estratégias adaptativas complexas, que são tanto meios quanto estão a serviço de um fim (Larrère, 2010, p. 407).

Há, então, fins na natureza. Pode-se considerar todo ser vivo, equivalente funcional de um conjunto de atos intencionais, como um "fim em si mesmo". Rolston III (1994a, p. 269), um dos teóricos do valor intrínseco, afirma que os organismos valorizam esses recursos de modo instrumental porque eles concordam com eles mesmos na forma de vida que eles têm, isto é, tendo um valor intrínseco imbuído. $\mathrm{Na}$ oposição entre os seres humanos e as coisas 
da natureza, característica do antropocentrismo, a multiplicidade de individualidades teleonômicas pretendidas são substituídas, ao mesmo tempo, por um fim em si mesmo e, então, têm um valor intrínseco (Taylor, 1981, 1986; Rolston III, 1994a, 1994b; Callicott, 1999).

Segundo essa perspectiva, todo indivíduo vivo é, portanto, igualmente com tudo o mais, digno de consideração moral para preservá-lo por si mesmo, independentemente da utilidade que tenha (Elliot, 2004, p. 398). É o que se compreende por caráter biocêntrico da ética ambiental.

Assim, em sentido geral, a fim de evitar ou atenuar o despojo ambiental diante dos interesses humanos, a justificativa da ética ambiental parte desse valor intrínseco da natureza, dela em si mesma, para (re)fundamentar as motivações do agir humano.

\section{Responsabilidade como proposta de ética}

\subsection{A natureza modificada do agir humano}

A relação ser humano-natureza na modernidade é considerada um problema ético na medida em que são percebidas e denunciadas as motivações ao agir humano sobre ela que violam ou desprezam a ideia recém apresentada do valor intrínseco da natureza. Tais motivações, em geral, baseiam-se na assertiva moderna de progresso, que tem em Bacon e Descartes alguns dos seus principais precursores. Nesse contexto, a ação humana está ligada à lógica de conceber a natureza como objeto, fruto de sua dominação e exploração por meio da técnica.
Com efeito, já no prefácio de $O$ princípio responsabilidade, Jonas (2006, p. 21) afirma: "Concebida para a felicidade humana, a submissão da natureza, na sobremedida de seu sucesso (...), conduziu ao maior desafio já posto ao ser humano pela sua própria ação". Historicamente, os processos de submissão da natureza se tornaram possíveis graças à utilização da técnica. Ela passou a ocupar um lugar de tanta importância na vida humana que a natureza de seu agir foi modificada, sendo possível afirmar que toda ação humana passou a ser mediada pelo meio técnico. Sobre essa natureza modificada da ação humana, Jonas afirma:

Tudo aí é novo, sem comparação com o que precedeu, tanto no aspecto da modalidade quanto no da magnitude: nada se equivale no passado ao que o homem é capaz de fazer no presente e se verá impulsionado a continuar fazendo, no exercício irresistível desse seu poder (Jonas, 2006, p. 21).

Foi a incorporação desse poder totalmente novo, conferido pela técnica moderna, que modificou a natureza do agir humano e atribuiu à humanidade uma capacidade transformadora nunca vista anteriormente. Ou seja, essa natureza modificada do agir nosso se dá pelo fato irreversível da técnica ter se tornado constitutivo irremediável na relação do ser humano com o mundo, componente inevitável, condição de vida essencial(izada) dessa relação nos dias de hoje, sem qualquer possibilidade de escolha (Galimberti, 2006, p. 8).

A ação humana teve seus limites ampliados progressivamente graças à melhoria contínua dos "meios", dos quais a técnica foi o principal, possibi- 
litando as chamadas revoluções tecnológicas. Porém é importante destacar que a técnica a qual Jonas se refere é a técnica moderna ${ }^{4}$ (JONAS, 2006, p. 29). Ao longo do tempo, ela representou uma mudança substancial no âmbito da práxis humana.

Assim, como a ética diz respeito aos fundamentos e motivações do agir humano e a técnica tendo invadido o campo da ação humana e modificado a natureza dessa ação, é justificada, portanto, a necessidade de mudança na ética, para além da ética tradicional.

Conforme Jonas afirma, a técnica moderna "introduziu ações de tal ordem inédita de grandeza, com tais novos objetivos e consequências que a moldura da ética antiga não consegue mais enquadrá-las" (Jonas, 2006, p. 39). Ou seja, as éticas da tradição (Jonas, 2006, p. 35-37) já não são mais suficientes no caminho de instrução sobre normas do "bem" e do "mal" que leve em conta as novas modalidades de seu poder e suas possíveis criações.

Em meio a essa exortação a uma nova instrução ética, o ambiente desconhecido das capacidades adquiridas pela sociedade por meio da tecnologia, o que pode servir como norte? Como colonizar o pensamento para uma nova teoria ética que mobilize o comprometimento humano com princípios que permitam deduzir as novas obrigações desse novo poder? É sobre essas questões que o texto busca responder, bem como destacar as principais características do princípio responsabilidade jonasiano como a proposição de uma nova ética que emerge do papel que a tecnologia passou a ocupar na vida social.

\subsection{O confronto à ética tradicional}

Para validar sua posição e destacar em que sentido ele se distancia da tradição, Jonas indica limites ou aspectos problemáticos da concepção de ação presentes na ética tradicional. Segundo o autor,

[t]oda ética até hoje - seja como injunção direta para fazer ou não fazer certas coisas ou como determinação dos princípios de tais injunções, ou ainda como demonstração de uma razão de se dever obedecer a tais princípios - compartilhou tacitamente os seguintes pressupostos inter-relacionados: (1) a condição humana, conferida pela natureza do homem e pela natureza das coisas encontra-se fixada de uma vez por todas em seus traços fundamentais; (2) com base nesses fundamentos, pode-se determinar sem dificuldade e de forma clara aquilo que é bom para o homem; (3) o alcance da ação humana e, portanto, da responsabilidade humana é definido de forma rigorosa. A argumentação que se segue pretende demonstrar que esses pressupostos perderam a validade e refletir sobre o que isso significa para a nossa situação moral (Jonas, 2006, p. 29).

\footnotetext{
${ }^{4}$ Nesse tocante, é importante a distinção entre a técnica moderna e técnica pré-moderna que ele faz em outra obra de sua autoria, Técnica, medicina e ética: sobre a prática do princípio responsabilidade (2013). A técnica pré-moderna, ou "dos tempos anteriores" (JONAS, 2006, p. 29), conforme referenciado em sua obra principal, tem uma série de atributos que a difere da técnica moderna. A técnica pré-moderna pode ser apreendida como uma posse, um estado, ou seja, ela se refere a uma certa constância ou uma certa tendência ao equilíbrio entre os fins e os meios. As revoluções que aconteceram sob esse viés se relacionam mais a casualidades que a intenções. Ao contrário, a técnica moderna se refere a um empreendimento, um processo em que, a cada novo passo em qualquer direção, não nos conduzimos a um ponto de equilíbrio ou saturação em que meios são adequados aos objetivos previamente fixados, mas contrariamente, em caso exitoso, constitui o motivo para dar outros passos em todas as direções possíveis (Jonas, 2013, p. 29).
} 
Fica visível sua intenção em deixar claro o caráter eminentemente antropocêntrico da ética tradicional, signo esse que se refere ao relacionamento direto dos seres humanos uns com os outros ou de cada ser humano consigo mesmo (Jonas, 2006, p. 35). Segundo ele, ao longo da tradição, a ética permaneceu centrada nos seres humanos e, inicialmente, reduzida ao ambiente da pólis, aspecto que confronta a Aristóteles diretamente. Segundo Jonas, para Aristóteles, “[q]ualquer que seja o bem ou o mal, ao qual o ser humano se veja impelido (...), eles ocorrem no interior do enclave humano, sem tocar a natureza das coisas" (Jonas, 2006, p. 33).

Por isso, os esforços no âmbito da filosofia moral sempre ignoraram o tema da relação ser humano-natureza. A natureza era um domínio não pertencente ao campo da ação humana, "não era objeto da responsabilidade humana, ela cuidava de si mesma" (Jonas, 2006, p. 33-34).

Todo o trato com o mundo extra-humano, isto é, todo o domínio da techné (habilidade) era - com exceção da medicina - eticamente neutro (...). Em suma, a atuação sobre objetos não humanos não formava um domínio eticamente significativo (Jonas, 2006, p. 35).

Outro aspecto limítrofe ou problemático, apontado por Jonas na ética da tradição, diz respeito ao alcance de sua ação no tempo e no espaço. O bem e o mal resultantes da ação eram valorados em um ambiente calculável e de curto prazo. Historicamente, pontos como a condição global da vida humana, a vida das gerações futuras e das outras espécies do planeta e o futuro distante não faziam parte das reflexões e proposições éticas. "O longo trajeto das consequências ficava ao critério do acaso, do destino ou da providência. Por conseguinte, a ética tinha a ver com o aqui e agora, como as ocasiões se apresentavam aos homens (...)" (Jonas, 2006, p. 35-36).

Desse modo, a relevância para o campo moral está no círculo imediato da ação. Os que vivem na mesma escala de tempo e espaço são os que têm alguma reinvindicação sobre a conduta do outro (seja pelo fazer ou deixar de fazer). De algum modo, isso fica evidente nas máximas da ética tradicional e nos mandamentos de cunho religioso, como: "Ama o teu próximo como a ti mesmo"; "Faze aos outros o que gostarias que eles fizessem a ti"; "Nunca trates os teus semelhantes como simples meios, mas sempre como fins em si mesmos".

O juízo de uma ação ser "boa" ou "má" é decidido no interior desse contexto de curto prazo. A autoria nunca é questionada, está relacionada à proximidade estabelecida no espaço, sua qualidade moral é imediatamente inerente a ela (Jonas, 2006, p. 37). Jonas define essa forma de pensar e agir como ética da simultaneidade ou do simultâneo (Jonas, 2006, p. 51).

Com esses dois aspectos limítrofes, ou seja, por meio desse caráter ligado ao presente e fortemente centrado no ser humano, tanto o futuro longínquo e imprevisível quanto a totalidade do mundo extra-humano (a biosfera) não são relevados na reflexão sobre os princípios morais. É justamente sobre essas limitações que Jonas afirma a necessidade de uma nova ética para esse novo tempo emergente.

O futuro e a própria natureza são condições de possibilidade de continuidade da humanidade e também espaço dos efeitos possíveis e longínquos da ação humana. Com efeito, a nova proposição de ética deve ter como horizonte temporal o futuro desconhecido, incluindo o direito daqueles que não existem (as futuras gerações) e ter como sujeito-alvo 
não somente a humanidade, mas a vida do cosmos, ou seja, todo ser que vive. A reinvindicação jonasiana é reconhecer a limitação da ética antropocêntrica para assumir uma ética bio ou cosmocêntrica.

Se assim for, isso requereria alterações substanciais nos fundamentos da ética. Isso significaria procurar não só o bem humano, mas também o bem das coisas extra-humanas, isto é, ampliar o reconhecimento de "fins em si" para além da esfera do humano e incluir o cuidado com estes no conceito de bem humano (Jonas, 2006, p. 41).

Para propor tamanha mudança no plano da filosofia moral e romper com os paradigmas da ética da tradição, Jonas não ignora completamente a herança tradicional deixada para a fundamentação de sua ética. Baseando-se em um percurso puramente kantiano, no estabelecimento de um novo imperativo, isto é, um princípio supremo, uma ordem geral que supere os dois aspectos destacados (a saber, o antropocentrismo e o caráter de simultaneidade), ele observa.

O imperativo categórico de Kant dizia: “Aja de modo que tu possas querer que tua máxima se torne lei universal". Aqui, o "que tu possas" invocado é aquele da razão e de sua concordância consigo mesma: a partir da suposição da existência de uma sociedade de atores humanos (seres racionais em ação), a ação deve existir de modo que possa ser concebida sem contradição, como exercício geral da comunidade (Jonas, 2006, p. 47).

Além disso, é importante salientar que a reflexão básica da moral não é propriamente moral, mas lógica, em "poder" ou "não poder" querer, revelando, portanto, o caráter de autocompatibilidade ou incompatibilidade, e não aprovação ou desaprovação moral. A essa observação, Jonas acrescenta que, em lugar da concordância consigo mesmo, é a ideia de que a vida humana e as demais formas de vida continuem como possíveis sobre a Terra, dependentes entre si. Ele reformula o imperativo, adequando-o ao novo tipo do agir humano, postulando: "Aja de modo a que os efeitos da tua ação sejam compatíveis com a permanência de uma autêntica vida humana sobre a Terra"; em sua forma negativa: "Aja de modo a que os efeitos da tua ação não sejam destrutivos para a possibilidade futura de uma tal vida" (Jonas, 2006, p. 47-48).

Em outras palavras, os conceitos de bem e de mal do agir humano determinam-se de modo que não coloque em risco a continuidade da vida humana e das futuras gerações. E sob a forma do novo imperativo, esse agir se torna coerente não pela compreensão do ato em si mesmo, mas a dos seus efeitos e consequências finais para a continuidade da atividade humana no futuro (Jonas, 2006, p. 49).

Com efeito, a ética jonasiana não invalida totalmente o legado da ética kantiana, pois, além de buscar fundamentar a sua proposta de ética por meio de um imperativo, esse imperativo também se relaciona com a ideia de dever. Dever esse que se relaciona principalmente com as próximas gerações. A diferença crucial entre ambas, a ética jonasiana e a ética kantiana, é que, para Jonas, a responsabilidade é fundamentada em uma relação assimétrica e não recíproca de cuidado, como em uma espécie de "mão-única" na qual o bem que fazemos não recebe ou reclama retribuição, enquanto, para Kant, trata-se de uma relação de iguais e, finalmente, de justiça e responsabilidade recíprocas entre os sujeitos envolvidos.

Mesmo baseando-se em um imperativo, um princípio de dever, a ética de Jonas é, também, consequencialista, apesar de distanciar-se do utilitarismo clássico. Sob uma perspectiva finalista, 
isto é, considerando os "efeitos finais" da ação no futuro, a ética da responsabilidade pode ser interpretada como uma ética utilitarista, no sentido de que as consequências produzidas pelas ações definem se estas são moralmente boas ou más. Em outras palavras, o juízo da ação moral depende do resultado da ação moral. Contudo, mesmo Jonas se referindo à previsão de um "futuro concreto", sua ética distancia-se do utilitarismo clássico, na medida em que não se trata meramente de calcular os efeitos finais das ações. Isso fica claro quando ele menciona os efeitos imprevisíveis e incalculáveis, os quais eliminam qualquer possibilidade de antecipação, em contraposição ao presente atual, totalmente contundente do que pode ser previsto. "O horizonte relevante da responsabilidade é fornecido muito mais pelo futuro indeterminado do que pelo espaço contemporâneo da ação" (Jonas, 2006, p. 44).

\subsection{A tecnologia como problema ético}

Superados os aspectos fundamentais da ética da tradição, Jonas constitui a sua proposta de ética para as gerações futuras levando em conta principalmente o papel que a tecnologia desempenha enquanto vetor interventivo e manipulador na atualidade. É porque a técnica, hoje em dia, interfere em quase tudo o que diz respeito ao ser humano - viver e morrer, pensar e sentir, agir e padecer, ambiente e coisas, desejos e destino, presente e futuro-, em suma, dado que ela se tornou um problema tanto central quanto ameaçador da existência humana global sobre a Terra, que ela, por meio disso, converte-se também numa questão da Filosofia. Com isso, faz-se necessário algo como uma Filosofia da Tecnologia (Jonas, 2013, p. 25).

Sua preocupação, aqui expressa, indica o quanto é inquietante e delicada a situação de uma sociedade que, progressivamente, estabelece como critério para avaliar o grau de seu desenvolvimento o avanço da ciência e da tecnologia. Pode-se dizer que o lugar central que as modernas tecnologias ocupam hoje tem início lá trás, com o ideal baconiano de dominação da natureza pela técnica científica, denunciando como essa concepção moderna de natureza, de submissão e dominação, problematizou-se socialmente.

"Saber é poder", como a máxima de Bacon, na sua firme disposição de ânimo em fazer do conhecimento científico um instrumento prático de controle da realidade (Reale; Antiseri, 1991, p. 329), acabou trazendo consequências desastrosas e, muitas delas, irreversíveis, com altos níveis de degradação ambiental. Semelhantemente, René Descartes, em seu Discurso do Método, disse que era possível ao ser humano obter conhecimentos que fossem úteis à vida e que a aplicação desses conhecimentos o tornaria senhor e possuidor da natureza (1996, p. 69).

Hodiernamente, o desenvolvimento científico e tecnológico da segunda metade do século XX contribuiu para se criar a ideia de autonomia da ciência, ascendendo radicalmente o seu status social ante a outras formas de conhecimento, incorporando inclu- 
sive uma espécie de caráter ideológico e assumindo, em si, todas as esferas da cultura (Marcuse, 1982).

Sobre a técnica, especificamente, Heidegger (1997) teorizou que o mundo humano tinha se transformado em um universo técnico, no qual todos estão presos. Ou seja, trata-se de uma civilização que se afirma em nível exclusivo do fazer, produzir, e na qual o compreender torna-se obsoleto e sem sentido. Em outras palavras, se antes da revolução industrial a techné era um tributo prestado à necessidade, agora, sob a forma da técnica moderna, é a mais significativa tarefa humana, tendo sido naturalizada como condição da ação humana. Em outras palavras, a tecnologia assumiu um significado ético por causa do lugar central que ela passou a ocupar subjetivamente nos fins da vida humana (Jonas, 2006, p. 43).

O homo faber triunfou sobre o homo sapiens. Nada é mais ameaçador do que esse sucesso da tecnologia. O domínio da natureza pela ciência e pela tecnologia se transforma no projeto central das sociedades modernas. A técnica avançou tanto que deixou de ser um simples meio e passou a ser, como tecnologia moderna, um fim em si mesmo.

Atualmente, somos condicionados a agir por meio da tecnologia - o que implicaria a ideia de prioridade das intenções (fins à procura de meios adequados); o que acontece é que a escolha dos fins é grandemente determinada pelas tecnologias (meios) disponíveis. Ou seja, a técnica moderna é que propõe essas finalidades, que seriam impossíveis de imaginar antes do seu aparecimento.

Na prática, o que ocorre é: para cada novo passo no desenvolvimento da técnica, surgem "novas necessidades", as quais demandam novos processos de desenvolvimento, que, por sua vez, propiciarão novas necessidades, gerando um ciclo vicioso e autônomo. Essa centralidade da técnica e sua autonomização promovem uma colonização cada vez maior sobre a esfera das relações do ser humano.

O domínio da técnica sobre a natureza gerou inúmeros resultados inesperados. A incrível extensão do poder alcançado pelo progresso técnico-científico, e da necessidade imperativa do seu emprego, fadou a humanidade, paradoxalmente, a uma espécie de impotência em administrar as consequências imprevisíveis e destrutivas desse mesmo progresso.

Nesse contexto, faz todo sentido ele apresentar, ainda no Prefácio de sua obra, o Prometeu desacorrentado como a figura metafórica que melhor representa o ser humano na era da técnica (Jonas, 2006 , p. 21) $)^{5}$. Livre, entregue a si mesmo e com poderes sempre mais eficazes que a ameaça iminente de um novo "castigo", coloca-se no destino daquele que se compadeceu com os humanos. "A promessa da tecnologia moderna se converteu em ameaça" (Jonas, 2006, p. 21).

Em última instância, por meio das modernas tecnologias, mais especificamente das biotecnologias, o próprio ser humano passou a figurar como objeto da técnica, possibilitando a introdução de elementos e características totalmente novas à própria natureza humana (Jonas, 2006, p. 57). O prolongamento da vida, o controle do comportamento humano e a manipulação genética são alguns

\footnotetext{
${ }^{5}$ Isto porque, na mitologia grega, Prometeu é um titã que defendeu a humanidade, conhecido por sua alta inteligência e por ter sido o responsável por roubar o fogo e ter dado aos mortais (seres humanos). Zeus, temendo que os mortais ficassem tão poderosos quanto os deuses, teria-o punido por esse crime, acorrentando-o a uma rocha por toda a eternidade.
} 
exemplos que demonstram, de forma contundente, essa diferenciação qualitativa no agir humano.

Cabalmente, nem a natureza nem a natureza humana podem ser tomadas como dados últimos e imutáveis para, com base neles, erguer-se uma avaliação ética dos efeitos da ação tecnológica. A grandeza desse poder mudou completamente a distância entre as questões presentes e remotas, entre os campos da prudência e da sabedoria.

A compreensão de que é, justamente, no triunfo da técnica que temos a latência de uma ameaça revela a necessidade de uma nova consideração a ser feita no âmbito da ética. E aqui aparece o principal sinal para uma resposta àquela sobreposição do homo faber ao homo sapiens: essa distorção ou inversão da figura humana demonstra a relevância de uma revisão dos princípios. "Se a esfera do produzir invadiu o espaço do agir essencial, então a moralidade deve invadir a esfera do produzir, da qual ela se mantinha afastada anteriormente" (Jonas, 2006, p. 44). Ou, em outras palavras, se a "ética tem a ver com o agir, a consequência lógica disso é que a natureza modificada do agir humano também impõe uma modificação na ética" (Jonas, 2006, p. 29).

A ação humana, tendo seu espectro hiperpotencializado, abriu o debate para um novo leque de questões e problemas que exigem o redimensionamento da reflexão ética e coloca no centro do debate um conceito já conhecido, mas que nunca esteve tão imbricado com esse desenvolvimento: a questão da responsabilidade. Ao invés de continuarmos na ilusória posição de segurança, como de quem controla o poder da técnica, é importante que desenvolvamos uma postura ética de reverência e de temor. Para isso, Jonas propõe que façamos uma heurística do temor, mecanismo de princípio e método no qual ele assenta a prática da responsabilidade enquanto proposta de ética.

\subsection{A heurística do temor}

Hoje em dia, não é a ausência de prognósticos ou de previsões (baseadas em pesquisas científicas) que faz o ser humano não se importar com o futuro. Todavia parece que a toada dessas projeções não influencia no modo de agir atual. É assumido o modo de vida presente na era da técnica como se este fora o modo natural de viver. A rapidez das mudanças e do ritmo de vida culminam cada vez mais para uma atitude de descarte do futuro em face do tempo presente.

Esse imediatismo do viver o "aqui e agora", por um lado, e o estado hipnótico provocado pela magia da técnica, por outro, eximem o ser humano contemporâneo de se preocupar com o futuro remoto. Diante desse quadro, por que querer fundamentar a ética para um novo agir por meio do temor? O que Jonas quer mostrar com essa apologia do medo? Isso tem a ver com uma ética dos sentimentos?

Jonas parte da constatação de que sabemos valorizar dialeticamente a vida como algo sagrado na medida em que conhecemos o que é sua aniquilação. Por exemplo, só reconhecemos a sacralidade da vida porque há assassinatos e, por meio do mandamento "não matarás", revela-se a vida como condição sagrada a ser preservada. Semelhantemente, só valorizamos a verdade porque há a mentira, só damos importância à liberdade se houver a ausência dela, como quando ficamos presos a um leito de hospital ou nos imaginamos em uma prisão (Jonas, 2006, p. 70). Ou seja, a perda de algo ou a mera representação de sua perda, pro- 
voca invariavelmente uma valorização do mesmo objeto em questão. Tais privações, reais ou fictícias (representações de privações), podem ter um efeito positivo sobre nossa disposição e sobre o nosso agir.

Por meio dessa perspectiva, Jonas entende que é possível que a previsão - não espontânea, mas intencional - de uma deformação do humano e da natureza possa contribuir para a preservação da humanidade e da natureza que queremos.

(...) assim também, em nosso caso, na busca de uma ética da responsabilidade a longo prazo, cuja presença ainda não se detecta no plano real, nos auxilia antes de tudo a previsão de uma deformação do homem, que nos revela aquilo que queremos preservar no conceito de homem. Precisamos da ameaça à imagem humana - e de tipos de ameaça bem determinados para, com o pavor gerado, afirmarmos uma imagem humana autêntica (Jonas, 2006, p. 70).

Desse modo, a heurística do medo, de Jonas, funciona como um atalho mental na tomada de decisões. Diante do reconhecimento ou emprego de juízo de valor de algo sendo bom ou mau, é muito mais fácil discernir aquilo que é mau. Trata-se de uma valoração mais imediata, mais urgente, bem menos passível de diferenças de opinião; mais que isso, ele não precisa ser procurado, é facilmente reconhecido: simplesmente, o mal nos impõe a sua existência, a sua presença como algo instantaneamente negado, enquanto o bem pode se fazer presente discretamente, sem ser, muitas vezes, notado, e continuar desconhecido, destituído de reflexão (Jonas, 2006, p. 71).

Segundo Jonas, é justamente a partir desta certeza que temos do mal que queremos evitar e a imprecisão e incerteza do bem que queremos (pois, sobre isso há muita discordância), que devemos delimitar o campo do exercício de nossa ação. Nisto consiste a heurística do medo (ou do temor): "O que nós não queremos, sabemos muito antes do que aquilo que queremos. Por isso, para investigar o que realmente valorizamos, a filosofia moral tem de consultar o nosso medo antes do nosso desejo" (Jonas, 2006, p. 71) ${ }^{6}$. Ou seja, sabemos muito bem o que queremos que não nos aconteça ou, simplesmente, temos consciência imediata sobre o que não queremos. Já para definir aquilo que queremos, talvez precisemos de muito mais tempo.

O mal vislumbrado nas consequências futuras de nossas opções e ações deveria servir de contraponto ao agir concreto aqui e agora. Esse mal imaginado, vislumbrado, deve assumir um caráter de $\mathrm{mal}$ experimentado. Eis o que o temor pode, segundo Jonas, oferecer enquanto princípio heurístico ${ }^{7}$ :

(...) o medo está presente na questão original, com a qual podemos imaginar que se inicie qualquer responsabilidade ativa: o que pode acontecer a ele, se eu não assumir a responsabilidade por ele? Quanto mais obscura a resposta, maior se delineia a responsabilidade. (...) A teoria da ética precisa tanto da representação do mal quanto da representação do bem, e mais ainda quando este último se tornou tão

\footnotetext{
${ }^{6} \mathrm{O}$ medo em lugar do desejo, historicamente, foi bem pouco considerado na ética. Na busca pelo conceito do bem, e isto é que realmente lhe importa, ela sempre costumou consultar o nosso desejo, sob o pressuposto socrático de que o que mais se deseja deve ser também o melhor. A exemplo disso, a ética utilitarista estabelece como princípio da filosofia moral "a maior felicidade de todos aqueles cujo interesse está em jogo, como sendo a justa e adequada finalidade da ação humana" (Bentham, 1974, p. 9).

${ }^{7}$ Heurística vem do grego "heuriskein", que significa achar, encontrar. Além disso, está relacionado à arte de inventar e à orientação, segundo métodos, para encontrar algo novo.
} 
borrado ao nosso olhar, necessitando ser ameaçado pela antevisão de novos males, para ganhar alguma nitidez (Jonas, 2006, p. 352).

Sumariamente e de forma prática, o primeiro dever da ética do futuro é: vislumbrar os efeitos de longo prazo de nossas ações. Pensar sobre as consequências da técnica, como de qualquer outra forma de ação humana, não apenas para o presente e sim considerando fundamentalmente o futuro, reformulando, finalmente, a ética.

A responsabilidade para Jonas, portanto, é compreendida como o princípio da ação humana que se projeta tanto no presente quanto no futuro. Segundo o contexto da sociedade tecnológica e seus problemas éticos, trata-se da doutrina moral diretamente incorporada ao processo tecnocientífico e em sentido de "poder como dever". O filósofo esclarece: "A responsabilidade é o cuidado reconhecido como obrigação em relação a um outro ser, que se torna 'preocupação' quando há uma ameaça à sua vulnerabilidade" (Jonas, 2006, p. 352).

Diante daquilo que é incerto e da ameaça que configura a tecnologia, a resposta que Jonas oferece é sempre precaução e cautela, pois, para ele, a ação deve ser medida em função dos seus piores prognósticos. Considerando as possibilidades de riscos e danos irremediáveis, inclusive para as gerações futuras, sua proposta é uma abordagem extremamente cuidadosa na avaliação das situações (Alencastro, 2009, p. 21). De modo conservador, a possibilidade escolhida é a ocorrência das piores situações, ou seja, "o saber origina-se daquilo contra o que devemos nos proteger" (Jonas, 2006, p. 71).

\section{Sustentabilidade e responsabilidade}

A julgar pelos discursos políticos dos últimos anos do século XX e, sobretudo, neste primeiro quarto do século XXI, é possível afirmar que a ideia de conservação do meio ambiente é uma ideia colonizada pela responsabilidade por um futuro melhor. Desde os primeiros alertas de crescimento populacional aos fatores de pressão ecológica sobre a natureza de seis décadas atrás, passou a atuar fortemente o movimento ambientalista no mundo, o qual teve aderência de diversos tipos de atores sociais ao imperativo do ecologicamente correto (Bursztyn \& Bursztyn, 2006, p. 54).

Nessa perspectiva, há uma clara relação entre o desenvolvimento das civilizações e os problemas ambientais. Isso porque, ao longo do tempo, a relação ser humano-natureza foi se modificando à medida que as necessidades humanas também mudavam (Souza, 2000). O resultado foi a constatação da apreensão de um alto poder destrutivo exploratório, predador sobre a natureza e até mesmo sobre si mesmo. Assim, foi sendo construída a compreensão sobre a necessidade de preservar, conservar a natureza, o meio ambiente, ou seja, cuidar dessa relação para a sua permanência, para que ela continuasse possível nos anos seguintes.

Todavia, passadas mais de seis décadas do soerguimento e amadurecimento da questão ambiental, considerando a história das revoluções humanas, esse tempo é relativamente curto e pode-se afirmar que a questão ambiental é ainda algo em construção. Se, de um lado, percebemos claramente os efeitos ou os problemas ambientais - como a incidência das mudanças climáticas, a escassez 
intensificada das fontes de energia não renováveis, a crescente produção de resíduos sólidos (compreendendo ampla gama de variedades e de longo ciclo de decomposição), o aumento do custo do acesso à água potável, a perda da biodiversidade animal e vegetal, dentre tantos outros -, do outro, ainda não temos a certeza científica em temas tão relevantes como as mudanças climáticas ${ }^{8}$.

Em contrapartida, a busca pelo progresso e crescimento na economia enquanto modelo de desenvolvimento social, promoveu qualidade de vida e trouxe benefícios sociais, mas também acarretou a degradação generalizada do meio ambiente, fazendo emergir, portanto, a preocupação ambiental e a busca de proteção do nosso planeta enquanto um bem necessário. Nesse contexto é que surge o tema da sustentabilidade.

A emergência da sustentabilidade como um valor capaz de promover mudanças estruturais no modo de vida da civilização atual é de uma abordagem recente e (ficará perceptível que) padece de ambiguidades e incertezas, mas compreende um vetor importante para compreender os problemas ambientais e enfrentar a crise ambiental atual.

Nesse contexto, considerando o primeiro mecanismo de regulação (o da ética) e depois de evidenciada a relevância da ética da responsabilidade como proposta de ética para os dias de hoje, será descrita uma breve evolução do debate ambiental no aparecimento da noção de sustentabilidade e, mobilizando os princípios da ética ambiental, discutido como essa noção qualitativa-valorativa revela a possibilidade de adoção da ética da responsabilidade como modelo de ética para uma sociedade com comportamentos mais sustentáveis.

\subsection{A emergência da noção de sustentabilidade}

Sustentabilidade é um termo antigo. De acordo com Boff (2012), ele surgiu na Alemanha em 1560, na Província da Saxônia, relacionado ao uso racional das florestas e de sua regeneração e manutenção permanente. Como um termo tomado da Ecologia enquanto ciência natural, diz respeito à tendência dos ecossistemas à estabilidade, à homeostase, ao equilíbrio dinâmico, baseado na interdependência e complementaridade da vida em suas formas mais diversificadas (Herculano, 1992, p. 12).

Com o passar do tempo, em um momento posterior à Revolução Industrial e às duas Grandes Guerras Mundiais, o ser humano entendeu que suas ações tinham grande poder de destruição sobre a natureza e ameaçavam a vida de seus semelhantes. Ademais, a percepção de que a produção e o consumo de forma exacerbada não perdurariam, devido à finitude dos recursos naturais e sua escassez (cada vez mais evidente nos últimos anos), foi sendo aguçada a busca por um valor, uma noção que continuasse tornando possível o tão desejado desenvolvimento (Souza, 2020; Nascimento, 2012).

Com a realização de conferências internacionais sobre o meio ambiente, como a de Estocolmo (1972) e Rio (1992) dentre as mais marcantes, sugeriu-se a ideia de desenvolvimento para além

\footnotetext{
${ }^{8}$ Por meio dos estudos do Painel Intergovernamental para Mudanças Climáticas (IPCC), que foi estabelecido pelas Nações Unidas e pela Organização Meteorológica Mundial em 1988, a comunidade científica, em geral, discute se a intensificação do efeito estufa, cujos males são sentidos por nós, resulta somente das emissões de gases ou se é devido em parte aos grandes ciclos naturais.
} 
da dimensão ambiental, compreendendo a social, que diz respeito à realidade da pobreza como fator provocador de agressões ambientais e que, por esse motivo, a sustentabilidade deve vislumbrar a equidade social e a qualidade de vida dessa geração e das próximas (Nascimento, 2012). Nesse contexto é que se faz pertinente a noção da sustentabilidade, sobretudo em sua dimensão da ética ambiental no dito desenvolvimento sustentável, na solidariedade com as próximas gerações e no modo como o ser humano se relaciona com a natureza. Esses aspectos podem sintetizar e evidenciar o quão importante é este debate para o planeta.

De acordo com Mantovaneli Júnior (2012), a grande questão do desenvolvimento sustentável é refletir de que maneira podemos utilizar com inteligência os recursos provenientes da natureza. Como essa utilização advém do agir por meio da técnica, que, por sua vez, como foi evidenciado anteriormente, implicou na modificação dos moldes da ética, quando se fala em desenvolvimento sustentável ou em sustentabilidade, é inevitável se discutir ética.

A palavra "sustentável" tem sua origem no latim sustenere, e significa sustentar, defender, conservar, cuidar. Desde o século XIII, é usada na língua inglesa, mas, somente depois dos anos 1980, passou a ser utilizada com mais frequência em outros lugares (Kamiyama, 2011).

Nos dicionários de língua portuguesa, a palavra "sustentabilidade" é conceituada como algo que possui qualidade ou condição do que é sustentável, um modelo de sistema que tem condições de se "sustentar" ou conservar. A reflexão sobre o tema "sustentabilidade" tem sido muito difundida nas últimas décadas, pois há um consenso mundial de que é preciso utilizar os recursos naturais de forma consciente e responsável (Souza, 2020). No entanto, a compreensão exata do que seja sustentabilidade é questionável, porque existem muitas interpretações sobre o termo, muitas vezes, divergentes:

Ainda não foram estabelecidos termos detalhados, por exemplo, quanto ao que poderia ser considerado um "futuro viável", contudo espera-se que esse futuro contenha proteção ambiental, consciência e responsabilidade do uso de recursos e o desenvolvimento humano com qualidade de vida (Souza, 2020, p. 28).

Sabe-se que "sustentabilidade" é um termo abrangente, isto é, integra processos econômicos, sociais, culturais e ambientais a nível global. Além disso, atrelado à noção de sustentabilidade está o processo de desenvolvimento de uma consciência ambiental.

O termo "desenvolvimento sustentável", embora tenha sua origem relacionada à ecologia, não pode ser desvinculado da economia. Herança da visão de desenvolvimento enquanto crescimento econômico (Veiga, 2008; 2015), a dimensão econômica acaba muitas vezes predominando no pensamento como objetivo superior e irrevogável.

No século XX, a partir da Segunda Guerra Mundial, a noção de sustentabilidade passou a ganhar forças, quando foram sentidas várias consequências de ordem social, econômica e, sobretudo, ambiental. Por conseguinte, com o desenvolvimento de uma política mundial para a gestão do meio ambiente, com a organização dos países em conferências e debates (Ribeiro, 2010), é que se passa a discutir os riscos ambientais advindos do progresso econômico.

Em 1972, em Estocolmo, na Conferência das Nações Unidas sobre o Meio Ambiente, a dimensão ambiental foi inserida na agenda internacional, legitimando uma preocupação generalizada sobre os 
problemas ambientais. Como produto dessa conferência, criou-se o Programa das Nações Unidas para o Meio Ambiente (PNUMA), tendo como principal função o estímulo a ações de proteção ambiental (Nascimento, 2012).

Em 1987, por meio da Comissão Mundial sobre Meio Ambiente e Desenvolvimento (CMMAD) da Organização das Nações Unidas (ONU) e coordenação da norueguesa Gro Harlem Brundtland, foi elaborado o relatório intitulado Nosso Futuro Comum, no qual se encontra a definição mais empregada de desenvolvimento sustentável: “[...] aquele que atende às necessidades do presente, sem comprometer a possibilidade de as gerações futuras atenderem as suas próprias necessidades" (CMMAD, 1988, p. 46). Esse documento apresentou a proposta de integrar a questão ambiental no desenvolvimento econômico. Dentre outras propostas, o relatório propunha que os governos adotassem medidas como: limitar o crescimento populacional, garantir alimentação a longo prazo, preservar a biodiversidade e os ecossistemas, estimular o uso de tecnologia onde pudessem ser utilizadas fontes de energia renováveis e estimular o desenvolvimento sustentável (Nobre, 1999; Ribeiro, 2010; Nascimento, 2012).

Sem dúvida, a definição de desenvolvimento sustentável foi um avanço para a época e colaborou para que mais tarde, no início da década de 1990, houvesse uma grande expansão do volume de legislações ambientais, assim como de acordos internacionais que impulsionaram a transformação da política ambiental global (Adams, 2006).

Na década de 1990, aconteceu no Rio de Janeiro o evento considerado o mais importante do século XX: a Conferência da Terra, também chamada de Rio 92 ou Eco-92. Graças a repercussão mundial desse evento, juntamente com o auxílio dos meios de comunicação, a expressão "desenvolvimento sustentável" e a ideia de sustentabilidade passaram a ser imediatamente aderidas aos discursos acadêmicos, às propostas dos políticos e empresários, às ideias de profissionais e militantes da área ambiental. Com isso, a expressão "desenvolvimento sustentável" começou a fazer parte do vocabulário cotidiano de vários seguimentos da população (Brunacci \& Philippi Júnior, 2005).

Mesmo tornando-se uma espécie de panaceia, como se, ao ser evocado, todos os males do mundo se resolvessem, por meio de sua principal concepção originada do Relatório Brundtland (1988) citada anteriormente, ela contém dois conceitos-chave: o conceito de necessidades, sobretudo as necessidades essenciais dos pobres no mundo, que devem receber a máxima prioridade; e a noção das limitações que o estágio da tecnologia e da organização social impõe ao meio ambiente, impedindo-o de atender às necessidades presentes e futuras (Bursztyn \& Bursztyn, 2006, p. 59).

Assim, cada autor busca inserir e precisar com mais detalhes aspectos que lhe parecem necessários na formulação. Novas adjetivações são agregadas à valoração sustentável do desenvolvimento: local, justo, solidário, includente, dentre outras.

Se, por uma via, há a plasticidade de definições em meio a preocupação com a precisão de aspectos que são relevantes e devem ser considerados, por outra, revela-se um tanto sintético em relação ao conteúdo e até motivado por ideologias individuais (Brunacci \& Philippi Júnior, 2005). Contudo a noção converge na crítica à economia industrial capitalista, devido aos preceitos lineares e em virtude das consequências no campo social e no campo ambiental (Boeira, 2012), e principalmente 
na busca por aspectos fundamentais, os quais, de acordo com Peter Nijkamp ${ }^{9}$, ficaram conhecidos como o tripé do desenvolvimento sustentável. A saber: economicamente viável, socialmente justo e ecologicamente equilibrado.

Buscando restringir, delimitar melhor a noção de sustentabilidade ainda sob a definição de desenvolvimento sustentável, Montibeller Filho (1993, p. 153) examina:

É desenvolvimento, porque não se reduz a um simples crescimento quantitativo. Pelo contrário, faz intervir a qualidade das relações humanas com o ambiente natural, e a necessidade de conciliar a evolução dos valores sócio-culturais com a rejeição de todo processo que leva à deculturação.

É sustentável, porque deve responder às necessidades da população atual, sem comprometer a capacidade das gerações futuras de responderem às suas.

Portanto é possível afirmar que a sustentabilidade se estabelece considerando três elementos constitutivos intrinsecamente relacionados entre si: a sociedade, a natureza e o tempo. A sociedade como autora dos processos de degradação ambiental e no que diz respeito à velocidade de utilização dos recursos naturais; a natureza no que se refere à velocidade de recuperação dos processos de degradação e de reposição desses recursos; e o tempo como condição de perduração das futuras gerações humanas e dos recursos naturais.

A sustentabilidade se estabelece como um valor na medida em que considera as ações humanas, que historicamente degradaram o meio ambiente, de modo a denotar a necessidade de mudança desse quadro para a mitigação dos efeitos da crise ambiental e equalização da relação ser humano-natureza, promovendo esforços equitativos entre crescimento econômico, justiça social e conservação ambiental.

\subsection{O que é que tem de sustentabilidade na ética da responsabilidade?}

Emblematicamente, por tudo isso, a ética da responsabilidade se apresenta como uma proposta de ética relevante na consideração da temática da sustentabilidade.

Assim como, historicamente, o desenvolvimento era medido somente em fins de crescimento econômico, dimensão que preconiza somente os interesses humanos e, portanto, de caráter puramente antropocêntrico, da mesma forma a ética, em seus moldes tradicionais, limitava a esfera de análise das ações humanas, restringindo-se ao ambiente do relacionamento do ser humano consigo mesmo (Jonas, 2006, p. 35). Ambas as questões se problematizam e se impõem socialmente no sentido de mostrar a importância do rompimento dos paradigmas consolidados e do movimento expansivo analítico.

A dimensão ética que a sustentabilidade traz em seu bojo considera a flutuação do regime de percepção fundado no antropocentrismo, nos interesses e necessidades humanas que se baseiam no crescimento econômico desenfreado e aumento da qualidade de vida irremediável, para uma espécie de equalização de direitos entre ser humano e natureza, de modo que se perfaz uma ética ambiental pragmática (Larrére, 2010). Além da tradicional

\footnotetext{
${ }^{9}$ Peter Nijkamp é professor de economia regional e urbana e de geografia econômica na VU University de Amsterdã.
} 
visão instrumental e antropocêntrica da natureza, na qual esta fornece recursos para a vida humana, ela detém, de forma dual, valor intrínseco que deve ser respeitado de forma responsável e administrado pela pessoa humana.

Não é necessário opor o valor intrínseco ao valor instrumental, é preciso fazer aparecer a diversidade de valores instrumentais. A utilidade não é somente imediata, ou material; é preciso levar em consideração que há um futuro e gerações futuras. Que há “interesses desinteressados”, como são os interesses estéticos ou cognitivos. Considerar a natureza como um conjunto de recursos, não é necessariamente se pôr a destruí-la: a natureza nos fornece sem dúvida diversos bens materiais (matérias-primas, produtos agrícolas etc.) que nós consumimos à medida que nos desenvolvemos, mas ela nos fornece também serviços ambientais (polinização, reciclagem de nutrientes, fixação dos nitratos, regulação homeostática) sem os quais nós não teríamos acesso aos bens e que está em nosso interesse manter em atividade, de modo algum fazer desaparecer (Larrére, 2010, p. 410). Pode-se distinguir, do tradicional antropocentrismo redutor, até mesmo denunciado pelas éticas bio ou ecocêntricas, um antropocentrismo ampliado ${ }^{10}$, tal como valorizar o homem não implica necessariamente desvalorizar a natureza.

Na medida em que o debate sobre desenvolvimento sob a ótica da sustentabilidade avançou, devido à escassez dos recursos naturais, à ocorrência dos desastres ambientais e aos demais processos de degradação, analogamente, a ética da responsabilidade se afirmou relevante no contexto de expandir o âmbito do agir humano, de forma a considerar não só a vida humana, mas as demais formas de vida também, ou seja, a natureza como objeto da filosofia moral. A ética jonasiana é pioneira nesse percurso porque, a partir das nuances construídas da dita ética tradicional, postula novos deveres do agir humano sob moldes de uma ética que repensa, justamente, a relação ser humano-natureza.

Isso graças aos efeitos produzidos pelo avanço da ciência e da técnica, os quais, invariavelmente, são os mesmos da política desenvolvimentista do crescimento econômico e, portanto, do antropocentrismo. Esse tipo de averiguação levou Jonas a consolidar a nova relação de responsabilidade com a natureza, que, mesmo identificando que esse antropocentrismo é incompatível com a realidade atual da vida humana, não anula por completo a herança deixada. O homem deve assumir uma postura de pertencimento e coexistência em relação à natureza, passando de senhor e possuidor da natureza para seu administrador, gerenciador (Larrère, 2010). Ou seja, coincidentemente, assim como a natureza é um elemento constitutivo da ideia de sustentabilidade como valor, ela é também objeto da ética sob o viés do princípio responsabilidade, de Jonas.

Analiticamente, se pudermos comparar o conceito de desenvolvimento sustentável do Relatório Brundtland - como "[...] aquele que atende às necessidades do presente, sem comprometer a possibilidade de as gerações futuras atenderem as suas próprias necessidades" (CMMAD, 1988, p. 46) - com a conjectura do novo imperativo ético jonasiano - "Aja de modo a que os efeitos da tua ação sejam compatíveis com a permanência de uma autêntica vida humana sobre a Terra" (Jonas, 2006, p. 47) -, o futuro como horizonte temporal,

\footnotetext{
${ }^{10}$ Às vezes chamado de "antropocentrismo fraco" (Hargrove, 1989).
} 
isto é, como condição de perduração das gerações humanas, é fator comum a ambas definições. O rompimento com a condição do tempo presente também é característica determinante quando se considera a utilização indiscriminada dos recursos naturais no impulso insaciável do crescimento econômico e a proposição da ética da responsabilidade na consideração das ações humanas que não coloquem em risco a continuidade da vida.

Em geral, o que é aspecto-chave para a mudança da relação ser humano-natureza é o reconhecimento de um direito moral próprio da natureza, que é fundamento da ética ambiental, reclamação da própria ética da responsabilidade e de que, de certo modo, a sustentabilidade se apropria enquanto valor. Sobre isso, Jonas observa:

Ao menos deixou de ser absurdo indagar se a condição da natureza extra-humana, a biosfera no todo e em suas partes (...) não se tornariam um bem a nós confiados, capaz de nos impor algo como uma exigência moral - não somente por nossa própria causa, mas também em causa própria e por seu próprio direito (Jonas, 2006, p. 41).

Em suma, nisso se relacionam e diferenciam a ética da responsabilidade e a noção da sustentabilidade em sua dimensão ética. $\mathrm{O}$ apontamento jonasiano para a importância das consequências de longo prazo das ações humanas sobre a natureza como um todo é reforçada pelo risco sobre a própria vida humana (aspecto que se mantém certo viés antropocêntrico), o que não anula o valor intrínseco da natureza, o qual é reconhecido e exige ser preservado.

Uma ética para o futuro, responsável e sustentável, que começa hoje, deve ter em vista as gera- ções vindouras, o vislumbre do amanhã e propor-se a proteger os futuros descendentes não só humanos, mas também não humanos, das consequências das ações presentes, as quais são executadas sob o signo da globalização da tecnologia, cujo potencial e consequências são imprevisíveis e potencialmente perigosas (Alencastro, 2009). O futuro deve ser incluído nas escolhas atuais, não se devendo escolher ou arriscar a não existência das próximas gerações por causa da presente-existente. Há agora, portanto, um dever para com o que ainda não existe também, perfazendo-se mais um elemento constitutivo da noção de sustentabilidade como valor: o tempo.

\section{Considerações finais}

A partir desta incursão, foi possível identificarmos os principais argumentos que estruturam a proposta de Jonas para uma nova ética. Começando pela consideração de que a técnica moderna introduziu uma modificação essencial na noção de ação humana, Jonas objetivou demonstrar que, mesmo com ela tendo se tornado nosso inevitável destino, é ainda possível a organização humana na instauração de um princípio de precaução e conservação como marco regulador de nossas ações. Todavia é relevante destacar que a sua proposta ética não se apresenta como um modelo acabado da ética normativa ou da ética ambiental.

A proposta de Jonas é fundamentada em duas críticas principais: no confronto às éticas da tradição e na crítica à técnica. Essa última se relaciona com a ideia moderna de progresso com vias de gerar o crescimento econômico, e com o ideal baconiano de dominação da natureza e utilização indiscriminada de seus recursos. Essa dominação, operada progres- 
sivamente por meio da técnica, aumentou exorbitantemente as capacidades e o poder da ação humana, constituindo-se, para o autor, ameaça iminente de autoaniquilação da própria espécie humana. Diante dessa ameaça, uma posição baseada em novos princípios - a responsabilidade, a qual se soma o temor e a reverência perante os riscos e estragos possíveis resultantes da ação humana - pode tornar possível pensarmos em uma posteridade, em um futuro menos doloroso para a natureza e sua diversidade de espécies, incluindo-se aí a espécie humana.

Semelhantemente, a sustentabilidade emerge como um valor que preconiza continuar tornando possível a utilização dos recursos naturais, porém, agora, de modo mais racional e inteligente, com ressalvas fundamentais ao reconhecimento do valor intrínseco que a natureza deve ter enquanto ser, sujeito de direito.

Dessa forma, por meio da inclusão da relação humana com a natureza (no que diz respeito aos esforços para a equalização dessa relação) e com o futuro desconhecido (na ampliação do horizonte temporal muitas vezes imprevisível) na base das preocupações éticas, a noção de responsabilidade ganha um novo sentido e conteúdo.

Nessa tônica, o princípio responsabilidade pode ser visto não como substituto, mas como complemento ou, até mesmo, atualização da ética, na medida em que os problemas dos tempos atuais exigem mais elementos e considerações do que a tradição oferece.

Por isso mesmo é que se perfaz um trabalho científico interdisciplinar, que extrapola o próprio âmbito restrito da ética filosófica, recorrendo à Grande Área das Ciências Ambientais na colabo- ração para o estabelecimento de um novo patamar de relações, de um novo lugar sobre os problemas ambientais: aquele que circunscreve o meio tecnocientífico.

Em decorrência das transformações na compreensão de desenvolvimento como crescimento econômico até se chegar à concepção, praticamente consensual, do desenvolvimento sustentável, a noção de sustentabilidade amplia o campo dos elementos para o desenvolvimento da vida humana, incorporando a qualidade ambiental como condição fundamental.

$\mathrm{O}$ que deve ser reforçado no agir humano contemporâneo é a consideração do valor intrínseco da natureza enquanto aspecto fundamental da nossa existência. Mesmo mantendo, em certa medida, caracteres antropocêntricos, deve ser reconhecida a importância da natureza por si só, independentemente de sua utilidade para a vida humana.

Pode-se afirmar que, sob a ótica do que se avança em termos de sustentabilidade como conceito-base para o desenvolvimento nos últimos anos, há uma compatibilidade entre o conceito de sustentabilidade e o princípio responsabilidade, podendo, pois, este ser utilizado como modelo de ética para uma sociedade que quer ser sustentável.

Reitera-se, portanto, que uma ética com o perfil proposto por Jonas pode lograr sucesso no fomento de uma sociedade com comportamentos mais sustentáveis. Em meio à motivação da crise ambiental em curso e o aparecimento e intensificação dos problemas ambientais em nosso tempo, por meio de um discurso aberto e crítico, mostra-se o teor importante de introduzir-se a responsabilidade para com o futuro no debate das questões éticas. 


\section{Referências}

Adams, W. M. The Future of Sustainability: Re-Thinking Environment and Development in the Twenty-First Century. Gland, Suiça: World Conservation Union, 2006.

Alencastro, M. S. Hans Jonas e a proposta de uma ética para a civilização tecnológica. Desenvolvimento e Meio Ambiente, 19, 13-27, 2009. doi: 10.5380/dma.v19i0.14115

Apel, K. O. Estudos de moral moderna. Petrópolis: Vozes, 1994.

Baudrillard, J. A transparência do mal: ensaios sobre os fenômenos extremos. Campinas: Papirus Editora. 1990.

Bentham, J. Uma introdução aos princípios da moral e da legislação. São Paulo: Editora Abril. 1974.

Boff, L. Sustentabilidade: o que é - o que não é. Petrópolis: Vozes, 2012.

Brunacci, A.; Philippi Júnior, A. Dimensão humana do desenvolvimento sustentável. In: Philippi Júnior, A.; Pelicioni, M. C. F. (Orgs.). Educação ambiental e sustentabilidade. Barueri: Manole, 2005.

Bursztyn, M. A. A.; Bursztyn, M. Desenvolvimento sustentável: biografia de um conceito. In: Nascimento, E. P.; Vianna, J. N. S. Economia, meio ambiente e comunicação. Rio de Janeiro: Garamond, 2006.

Callicott, J. B. Intrinsic value in nature: A metaethical analysis. In: Beyond the Land Ethic: More Essays in Environmental Philosophy. State University of New York Press, p. 239-261, 1999.

Comissão Mundial sobre Meio Ambiente e Desenvolvimento. Nosso futuro comum. Rio de Janeiro: Fundação Getúlio Vargas, 1988.

Descartes, R. Discurso do método. São Paulo: Martins Fontes, 1996.

Elliot, R. La ética ambiental. In: Singer, P. (Org.). Compendio de ética. Madrid: Alianza Editorial, p. 391-404, 2004.

Galimbert, U. Psiche e Techne: o homem na idade da técnica. São Paulo: Paulus, 2006.
Hargrove, E.C. Foundations of Environmental Ethics. Prentice Hall, 1989.

Heidegger, M. A questão da técnica. In: Cadernos de Tradução, São Paulo: USP, 2. ed., 1997.

Herculano, S. Desenvolvimento Sustentável: como passar do insuportável ao sofrível. Tempo e Presença Digital, (14)261, 12-15, 1992.

Jonas, H. Técnica, medicina e ética: sobre a prática do princípio responsabilidade. São Paulo: Paulus, 2013.

Jonas, H. O princípio responsabilidade: Ensaio de uma ética para a civilização tecnológica. Rio de Janeiro: Contraponto/ Editora PUC-Rio, 2006.

Kamiyama, A. Desenvolvimento sustentável. In: São Paulo (Estado). Secretaria do Meio Ambiente/Coordenadoria de Biodiversidade e Recursos Naturais. $2^{\circ}$ Congresso de Pesquisa Científica: Inovação, Ética e Sustentabilidade. Agricultura sustentável. São Paulo: SMA, 2011.

Kant, I. Fundamentação da Metafísica dos Costumes. Coleção Os Pensadores. São Paulo: Abril Cultural, 1984.

Larrère, C. Les éthiques environnementales. Natures Sciences Sociétés, 18(4), 405-413, 2010. doi: 10.1051/ nss $/ 2011004$

Light, A. Environmental ethics. In: Frey, R. G.; Wellman, C. H. (Orgs.). A companion to applied ethics. Blackwell Publishing, 2005 [2003].

Mantovaneli Júnior, O. A sustentabilidade como projeto da cidadania planetária. In: Phillipi Júnior, A.; Sampaio, C. A. C.; Fernandes, V. (Orgs.). Gestão de natureza pública e sustentabilidade. São Paulo: Editora Manole (Coleção Ambiental), 2012.

Marcuse, H. A Ideologia da Sociedade Industrial: o homem unidimensional. Rio de Janeiro: Zahar, 1982.

Montibeller Filho, G. Ecodesenvolvimento e desenvolvimento sustentável: conceitos e princípios. Textos de economia, 4(1), 131-142, 1993.

Nascimento, E. P. do. Trajetória da sustentabilidade: do ambiental ao social, do social ao econômico. Estudos Avançados, 74(26), 51-64, 2012. doi: 10.1590/S010340142012000100005 
Nobre, M. Desenvolvimento sustentado e problemática ambiental. Lua Nova, 47, 137-250, 1999. doi: 10.1590/ S0102-64451999000200008

Reale, G.; Antiseri, D. História da filosofia: do romantismo até nossos dias. São Paulo: Paulus, 1991.

Ribeiro, W. C. A Ordem ambiental internacional. São Paulo: Contexto, 2. ed., 2010.

Rolston III, H. Value in nature and the nature of value, reproduit. In: Light, A.; Rolston III, H. (Orgs.). 2003. Environmental Ethics: An Anthology. Malden (MA), Blackwell Publishing, p. 143-153, 1994a.

Rolston III, H. Conserving Natural Value. New York: Columbia University Press, 1994b.

Routley, R. Is there a need for a new, an environmental, ethic? In: Proceedings of the XV World Congress of Philosophy, Varna, Bulgária, 17-22 de set., 1973, Sofia Press, p. 205-210, 1973.
Souza, A. B. A dimensão ética da Sustentabilidade. São Cristóvão, Dissertação (Mestrado em Desenvolvimento e Meio Ambiente) - UFS, 2020.

Taylor, P. W. The ethics of respect for nature. Environmental Ethics, 3(3), 197-218, 1981.

Taylor, P.W. Respect for Nature: A Theory of Environmental Ethics. Princeton (NJ): Princeton University Press, 1986.

Veiga, J. E. da. Desenvolvimento sustentável: o desafio do século XXI. Rio de Janeiro: Garamond, 3. ed., 2008.

Veiga, J. E. Para Entender o Desenvolvimento Sustentável. São Paulo: Editora 34, 2015. 